\title{
Is There a Correlation Between Airway Volume and Maximum Constriction Area Location in Different Dentofacial Deformities?
}

\author{
Liseane F. dos Santos, DDS, MSD, ${ }^{\star}$ David A. Albright, DDS, MSD, $\dagger$ \\ Vinicius Dutra, DDS, MBA, PhD, $\ddagger$ Surya S. Bhamidipall, MHP, $\S$ \\ Kelton T. Stewart, DDS, MS, // and Waldemar D. Polido, DDS, MS, PhD ף
}

Purpose: The purpose of the present study was to correlate the airway volume and maximum constriction area (MCA) with the type of dentofacial deformity in patients who had required orthognathic surgery.

Materials and Methods: The present retrospective cohort study included orthognathic surgery patients selected from the private practice of one of us. The selected cases were stratified into 5 different groups according to the clinical and cephalometric diagnosis of their dentofacial deformity. The preoperative airway volume and anatomic location of the MCA were calculated using the airway tool of the Dolphin Imaging software module (Dolphin Imaging and Management Solutions, Chatsworth, CA) and correlated with the diagnosed dentofacial deformity. Differences in the pretreatment airway volumes and MCA location were compared among the deformities.

Results: The MCA location was more often the nasopharynx for maxillary deficiency and the oropharynx for mandibular deficiency deformities. The nasopharynx volume was significantly smaller statistically $(P<.005)$ for maxillary deficiency plus mandibular excess compared with mandibular deficiency. The hypopharynx volume was significantly smaller statistically $(P<.005)$ for vertical maxillary excess plus mandibular deficiency than for both maxillary deficiency and maxillary deficiency plus mandibular excess. No statistically significant difference was found among the different deformity groups in relation to the mean airway volume $(P>.005)$.

Conclusions: The location of the airway MCA seems to have a strong correlation with the horizontal position of the maxilla and mandible. The MCA in maxillary deficiencies (isolated or combined) was in the nasopharynx, and the MCA in mandibular deficiencies (isolated or combined) was in the oropharynx. Clinicians should consider these anatomic findings when planning the location and magnitude of orthognathic surgery movements to optimize the outcomes.

(C) 2020 Published by Elsevier Inc. on behalf of the American Association of Oral and Maxillofacial Surgeons

J Oral Maxillofac Surg $\mathbf{\square}$ :1.e1-1.e10, 2020

\footnotetext{
*Orthodontics Resident, Department of Orthodontics and Oral Facial Genetics, Indiana University School of Dentistry, Indianapolis, IN.

$\dagger$ Visiting Clinical Assistant Professor, Indiana University School of Dentistry, Indianapolis, IN.

$\ddagger$ Clinical Associate Professor, Department of Radiology, Indiana University School of Dentistry, Indianapolis, IN.

$\S$ Statistician, Indiana University School of Medicine, Indianapolis, IN.

\|Professor and Chairman, Department of Orthodontics and Oral Facial Genetics, Indiana University School of Dentistry, Indianapolis, IN.

\Clinical Professor, Department of Oral and Maxillofacial Surgery, Indiana University School of Dentistry, Indianapolis, IN.
}

Conflict of Interest Disclosures: None of the authors have any relevant financial relationship(s) with a commercial interest.

Address correspondence and reprint requests to Dr Polido: Department of Oral and Maxillofacial Surgery, Indiana University School of Dentistry, W Michigan St, Office DS 126, Indianapolis, IN 46202; e-mail: wdpolido@iu.edu

Received July 102019

Accepted March 192020

(c) 2020 Published by Elsevier Inc. on behalf of the American Association of Oral and Maxillofacial Surgeons 0278-2391/20/30318-9 hitps://doi.org/10.1016/i.joms. 2020.03.024

This is the author's manuscript of the article published in final edited form as: dos Santos, L. F., Albright, D. A., Dutra, V., Bhamidipalli, S. S., Stewart, K. T., \& Polido, W. D. (2020). Is There a Correlation Between Airway Volume and Maximum Constriction Area Location in Different Dentofacial Deformities? Journal of Oral and Maxillofacial Surgery. 
The interdependence between the skeletal position of the maxilla and mandible, the soft tissues associated with them, and the musculature that holds and maintains the airway can reveal how the skeletal pattern affects the position, shape, and size of the airway passage. ${ }^{1,2}$ Previous studies have used 2-dimensional (2D) lateral cephalometric radiographs to analyze the airway before and after orthognathic surgery. ${ }^{3,4}$ Considering that the airway is a 3-dimensional (3D) structure, $2 \mathrm{D}$ images produce issues with magnification, superimposition of bilateral structures, and distortion, making them less reliable than $3 \mathrm{D}$ computed tomography (CT) scans. ${ }^{5}$ 3D images obtained with CT and cone-beam CT (CBCT) have been used to examine the pharyngeal airway space (PAS), with appropriate software. ${ }^{6-9}$ The use of specific software tools facilitate acquisition of the volume and area of the upper airway, the manipulation of images, and planning surgery. ${ }^{7,10-12}$ Because of these many advantages, CBCT has been increasingly used by professionals working in the craniofacial region, and more accurate PAS analysis has become a key component in the comprehensive evaluation of patients. $^{13,14}$

In 2015, Castro-Silva et al $^{1}$ analyzed the PAS of 60 patients using 3D images and Dolphin Imaging software (Dolphin Imaging and Management Solutions, Chatsworth, CA). The patients were divided into 3 groups according to their dental and skeletal malocclusion and assessed using clinical and cephalometric analyses. The results showed that the mean volume and area for skeletal Class III patients were greater than those for skeletal Class I and II patients. In 2018, Shokri et al ${ }^{15}$ compared the PAS of 71 patients using CBCT. They classified 3 groups according to skeletal malocclusion in Class I, II, and III to analyze the differences among the airway volume, airway area, minimum axial area, mean airway area, and airway morphology. Their findings showed a correlation between the skeletal facial pattern and upper airway dimensions. Likewise, the total airway volume and mean airway area of the Class III patients were larger than those of the Class II patients.

These previous studies attempted to correlate the airway volume with the type of occlusion, without clearly specifying the facial characteristics of the deformity. Anatomic deformities of the soft tissue and craniofacial skeletal can modify the pharyngeal airway space and can be modified by the surgical procedure. Despite the correction of the occlusion, the clinical correlation with the location of the main deformity and the airway must be properly assessed to implement proper planning and obtain improved airway outcomes, with correct occlusion and balanced facial esthetics. $^{16}$
Hence, the purpose of the present retrospective study was to assess the posterior airway volume and the location of the maximum constriction area (MCA) in patients who had presented for correction of a dentofacial deformity through orthognathic surgery. We sought to correlate the posterior airway volume and MCA location with the type of facial deformity, diagnosed both clinically and cephalometrically. Our hypothesis was that the location of the MCA and an airway area with a smaller volume would have a direct relationship with the clinical diagnosis of the deformity and, hence, would influence the surgeon's decision regarding the correct procedure to be performed.

\section{Materials and Methods}

\section{POPULATION AND SELECTION CRITERIA}

The present study used a retrospective case series study design. The Indiana University institutional review board approved the present study (approval no. 1901123949). Patients were included in the present study if they had met the following inclusion criteria: 1) availability of an immediately preoperative full face CBCT scan; 2) CBCT images acquired using the same equipment for each individual patient; and 3) preoperative face and occlusion photographs to confirm the clinical diagnosis of the deformity. The exclusion criteria were as follows: 1 ) documented or suspected craniofacial syndromes; 2) maxillomandibular asymmetries; 3) isolated transverse maxillary deficiency; 4) full edentulism; and/or 5) previous orthognathic surgery.

The chief request of all patients was correction of the occlusion, with improvements in facial esthetics. None of the patients had reported correction of sleep apnea as their chief complaint. The body mass index (BMI) was not recorded for our population, because no patient was considered obese or significantly overweight.

\section{METHODS}

The selected patients were stratified according to the clinical and cephalometric diagnosis of their dentofacial deformity into 5 different clinically identified groups. The upper airway boundaries were defined and segmented in 3 different anatomic areas (ie, oropharynx, nasopharynx, hypopharynx). The MCA was identified for the complete volume of the upper airway. The correlation between the diagnosed dentofacial deformity with the location and volume of the 3 different segments of the airway and the location of the MCA was evaluated. The results were analyzed statistically. 


\section{CLINICAL ANALYSIS}

Standardized facial and intraoral photographs were taken of all subjects. These included frontal, frontal smiling, and profile photographs of the face and frontal, right, and left photographs of the occlusion, which were analyzed to define the clinical diagnosis.

\section{CBCT IMAGING ACQUISITION}

CBCT images were obtained preoperatively. The patients were positioned for CBCT acquisition in an upright position. All CBCT images were acquired at the same facility using the iCAT Next Generation Dental Imaging System (Imaging Sciences International, Hatfield, PA). The protocol for image acquisition was 26.9 seconds and $0.3-\mathrm{mm}$ slices. The tomography apparatus was adjusted for $120 \mathrm{KVp}$ and $5 \mathrm{~mA}$, using a field of view of $170 \times 230 \mathrm{~mm}$. Each patient was instructed to hold still, to not swallow, and to breathe smoothly during image acquisition. Additionally, they were requested to keep their teeth in occlusion, with their head position upright, lips relaxed, and the Frankfort plane parallel to the floor. In patients with a clinically diagnosed centric relation-centric occlusion discrepancy, an occlusal splint was constructed using bite registration material, and the patients were instructed to wear it when undergoing CBCT. The obtained images were stored in digital file format (digital imaging communication in medicine [DICOM]). The CBCT images were coded and the analysis performed by a single examiner (L.S.). The CBCT DICOM files were uploaded into Dolphin imaging software (Dolphin Imaging and Management Solutions), and the changes in the airway volume and MCA were analyzed on the same computer with similar evaluation conditions. The 3D volumetric images were oriented using the Dolphin Imaging software as follows: the midsagittal plane was adjusted to match the skeletal midline of the face, and the axial plane was adjusted to the Frankfort horizontal plane.

\section{IMAGING ANALYSIS WORKFLOW}

The patients' DICOM files were imported into the Dolphin software (Dolphin Imaging and Management Solutions). The initial lateral cephalometric images were created from the CBCT scans using a dedicated tool from Dolphin. The cephalometric parameters used to assist in determining the dentofacial deformity were those reported in the McNamara cephalometric analysis. ${ }^{16}$ The reference used to assess the anteroposterior positions of the maxilla and mandible was a line perpendicular to the Frankfort horizontal plane drawn through the nasion. In a well-balanced face, the A point should be positioned within $1 \mathrm{~mm}$ of this line and the $B$ point 0 to $4 \mathrm{~mm}$ behind this line. The patients were considered to have maxillary deficiency if the A point was more than $1 \mathrm{~mm}$ behind the nasion-perpendicular (N-P) line. If the $B$ point was more than $4 \mathrm{~mm}$ behind the line, mandibular deficiency was the diagnosis, and if the $\mathrm{B}$ point was positioned ahead of the N-P line, the diagnosis was mandibular excess.

By observing the intraoral and face photographs and the cephalometric data, the deformities were classified into the following clinical aspect groups:

1. Maxillary deficiency

2. Mandibular deficiency

3. Mandibular excess

4. Vertical maxillary excess

5. A combination of these deformities (2-jaw deformity)

\section{AIRWAY MEASUREMENTS}

The boundaries and landmarks (Table 1) were identified using a previously described 3D method (Fig 1). ${ }^{8,16}$ Once the CBCT scan was positioned according to the reference planes and landmarks, the sinus/ airway tool was activated, and the external limits of the nasopharynx (Fig 1A), oropharynx (Fig 1B), and hypopharynx (Fig 1C) were delineated. The software calculated the volume of the respective delineated regions. The MCA location for the entire upper airway volume was also assessed using the sinus/airway tool. For all airway analysis calculations, the airway sensitivity level was adjusted to 50, which, in the Dol-Q6 phin software, visually represents the complete fill of the airway space, in the marked area. The results of the airway volume measurements were registered using a password-protected Excel sheet.

\section{RELIABILITY ASSESSMENT}

The diagnostic records (profile photographs and lateral cephalograms) of 5 patients were used to assess the reliability with the diagnosis. Two of us (L.S. and W.D.P.) diagnosed the 5 cases according to the established parameters and then repeated the process 1 week later to establish the intra- and interexaminer reproducibility for the clinical diagnosis.

To evaluate the intra- and interrater reliability of the imaging findings, the CBCT scans of 5 patients were identified. Using these CBCT scans, the airway regions of interest were calculated by 2 of us (L.S. and K.S.). The same CBCT scans were used to evaluate the airway again 1 week later, and the results were compared for intra- and interexaminer agreement.

Intraclass correlation coefficients and Bland-Altman plots were used to evaluate the within-investigator repeatability and the between-investigator reproducibility. Acceptable levels of agreement were achieved 
Table 1. DEFINITION OF ANATOMIC AREAS

\begin{tabular}{|c|c|c|}
\hline \multicolumn{3}{|l|}{ Nasopharynx } \\
\hline Anterior limit & Anterior limit of upper airway & Line extending from $S$ to PNS \\
\hline Posterior limit & Posterior limit of upper airway & Line from $\mathrm{S}$ to tip of $\mathrm{OP}$ \\
\hline Inferior limit & Inferior limit of upper airway & Line from PNS to OP \\
\hline \multicolumn{3}{|l|}{ Oropharynx } \\
\hline Superior limit & Superior limit of lower airway & Line extending from PNS to OP \\
\hline Inferior limit & Inferior limit of lower airway & $\begin{array}{l}\text { Line extending from base of epiglottis to posterosuperior base } \\
\text { of CV4 }\end{array}$ \\
\hline Anterior limit & Anterior limit of lower airway & Line extending from PNS to base of epiglottis \\
\hline Posterior limit & Posterior limit of lower airway & Line extending from tip of OP to posterosuperior corner of CV4 \\
\hline \multicolumn{3}{|l|}{ Hypopharynx } \\
\hline Superior limit & Superior limit of lower airway & $\begin{array}{l}\text { Line extending from base of epiglottis to posterosuperior corner } \\
\text { of CV4 }\end{array}$ \\
\hline Inferior limit & Inferior limit of lower airway & $\begin{array}{l}\text { Line extending from posteroinferior corner of CV4 to inferior } \\
\text { border of symphysis }\end{array}$ \\
\hline Anterior limit & Anterior limit of lower airway & $\begin{array}{l}\text { Line extending from base of epiglottis to inferior border of } \\
\text { symphysis }\end{array}$ \\
\hline Posterior limit & Posterior limit of lower airway & $\begin{array}{l}\text { Line extending from posterosuperior corner of } \mathrm{CV} 4 \text { to } \\
\text { posteroinferior corner of } \mathrm{CV} 4\end{array}$ \\
\hline
\end{tabular}

Abbreviations: CV4, cervical vertebra 4; OD, odontoid process; PNS, posterior nasal spine; S, sella.

dos Santos et al. Correlation Between Airway Volume and MCA Location. J Oral Maxillofac Surg 2020.

by the examiners for both the airway assessment and the subject diagnosis.

\section{STATISTICAL ANALYSIS}

A descriptive statistical analysis was performed of the sample. The measurements for the total and segmented volumes and the anatomic location of MCA were correlated with the type of dentofacial deformity. The post hoc calculation showed $80 \%$ power to detect the total volume differences of $\sim 15,000$ or less, depending on the specific group comparison. Differences smaller than this were not significant for the present study, because they represented smaller changes.

Differences between the deformity categories for the baseline total airway volume, nasopharynx volume, oropharynx volume, and hypopharynx volume were analyzed using analysis of covariance to identify the effects of different combinations of deformity categories, with age and gender included as covariates. Post hoc pairwise comparisons between the deformity categories were performed using the Fisher protected least significant differences test. All pairwise comparisons were performed at the $5 \%$ significance level. Analysis assumptions were evaluated and satisfied. All analyses were performed using SAS, version 9.4 (SAS Institute Inc, Cary, NC).

Differences between the deformity categories for the baseline total airway volume, nasopharynx volume, oropharynx volume, and hypopharynx volume were analyzed using analysis of covariance to identify the effects of different combinations of deformity categories, with age and gender included as covariates. Post hoc pairwise comparisons between deformity categories were performed using the Fisher protected least significant differences test. All pairwise comparisons were performed at the 5\% significance level. Analysis assumptions were evaluated and satisfied. All analyses were performed using SAS, version 9.4 (SAS Institute Inc).

\section{Results}

The study population was selected from among 87 patients who had presented to the private practice of the surgeon (W.D.P.) for the evaluation and management of their dentofacial deformity from January 9, 2013 and February 9, 2017. At the initial screening, 41 patients had met the inclusion criteria. The mean patient age for the 41 included patients was 28 years (range, 16 to 55 years). The descriptive initial data are presented in Table 2.

\section{TOTAL AIRWAY VOLUME}

The mean total airway volumes for the different facial deformities were as follows: $22,986.67 \mathrm{~mm}^{3}$ for mandibular deficiency, $23,027.25 \mathrm{~mm}^{3}$ for maxillary deficiency, $25,785.40 \mathrm{~mm}^{3}$ for maxillary deficiency plus mandibular deficiency, $24,912.20 \mathrm{~mm}^{3}$ for maxillary deficiency plus mandibular excess, and 


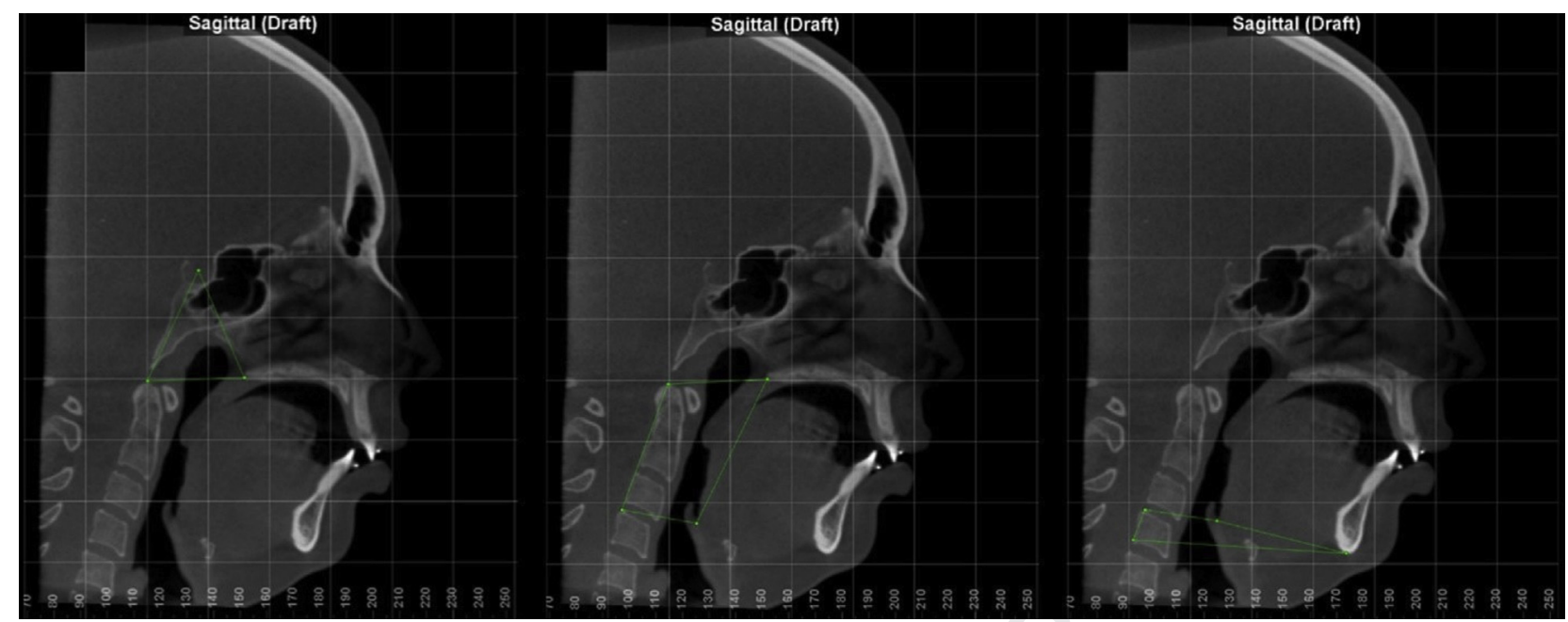

FIGURE 1. Images depicting Left, upper airway boundaries, nasopharynx; Middle, lower airway boundaries, oropharynx; and Right, lower airway boundaries, hypopharynx.

dos Santos et al. Correlation Between Airway Volume and MCA Location. J Oral Maxillofac Surg 2020.

$20,225.25 \mathrm{~mm}^{3}$ for vertical maxillary excess plus mandibular deficiency. No statistically significant differences were found among the different deformity groups in relation to the mean airway volume.

When comparing the sample according to gender, the women had a larger mean airway volume $\left(24,669.61 \mathrm{~mm}^{3}\right)$ compared with the men $\left(21,835.38 \mathrm{~mm}^{3}\right)$. However, this difference was not statistically significant.

Analyzing the segmented airway volumes by location in the different dentofacial deformities, the nasopharynx volume was significantly smaller for maxillary deficiency plus mandibular excess

\begin{tabular}{|c|c|}
\hline Variable & n (\%) \\
\hline \multicolumn{2}{|l|}{ Gender } \\
\hline Female & $28(68.3)$ \\
\hline Male & $13(31.7)$ \\
\hline \multicolumn{2}{|l|}{ Deformity category } \\
\hline Mandibular deficiency & $9(22.0)$ \\
\hline Maxillary deficiency & $8(19.5)$ \\
\hline $\begin{array}{l}\text { Maxillary } \\
\text { deficiency + mandibular } \\
\text { deficiency }\end{array}$ & $5(12.2)$ \\
\hline $\begin{array}{l}\text { Maxillary } \\
\text { deficiency + mandibular } \\
\text { excess }\end{array}$ & $15(36.6)$ \\
\hline $\begin{array}{l}\text { Maxillary } \\
\text { excess }+ \text { mandibular } \\
\text { deficiency }\end{array}$ & $4(9.8)$ \\
\hline
\end{tabular}

dos Santos et al. Correlation Between Airway Volume and MCA Location. J Oral Maxillofac Surg 2020. compared with mandibular deficiency $(P=.0330)$. The hypopharynx volume was significantly smaller for vertical maxillary excess plus mandibular deficiency compared with maxillary deficiency $(P=.0297)$ or maxillary deficiency plus mandibular excess $(P=.0437)$. Generally, the nasopharynx volume was significantly smaller statistically for the groups with maxillary deficiency compared with the groups with mandibular deficiency. The data are detailed in Table 3.

\section{MAXIMUM CONSTRICTION AIRWAY}

The MCA mean volume found in the established airway regions were as follows: hypopharynx, $109.13 \mathrm{~mm}^{2}$; nasopharynx, $179.29 \mathrm{~mm}^{2}$; and oropharynx, $149 \mathrm{~mm}^{2}$. The comparison of the MCA volume between the groups showed no statistically significant differences among the dentofacial deformities $(P=.6333)$.

The location of the MCA was in the oropharynx in 19 patients, nasopharynx in 14 patients, and hypopharynx in 8 patients (Table 4). In examining the dentofacial deformity groups more broadly, a trend was noted. Patients with maxillary deficiencies (Fig 2) more commonly exhibited the MCA in the nasopharynx (13 patients), followed by the oropharynx (9 patients) and hypopharynx (6 patients). Patients with mandibular deficiencies (Fig 3) demonstrated a different MCA location distribution, with most patients having the MCA in the oropharynx (13 patients), followed by the nasopharynx ( 3 patients) and hypopharynx ( 2 patients). The correlations of these locations with the respective dentofacial deformities and gender are depicted in Table 5. 


\section{Table 3. REPORT OF DATA STRATIFIED BY OUTCOME}

\begin{tabular}{|c|c|c|c|c|}
\hline Predictor & Patients (n) & Mean \pm SD $\left(\mathrm{mm}^{3}\right)$ & $\operatorname{Median}\left(\mathrm{mm}^{3}\right)$ & Range $\left(\mathrm{mm}^{3}\right)$ \\
\hline \multicolumn{5}{|l|}{ Total volume } \\
\hline \multicolumn{5}{|l|}{ Deformity } \\
\hline Mandibular deficiency & 9 & $22,987 \pm 5,522$ & 20,833 & $16,050-32,700$ \\
\hline Maxillary deficiency & 8 & $23,027 \pm 7,908$ & 24,440 & $10,667-35,074$ \\
\hline $\begin{array}{l}\text { Maxillary deficiency + mandibular } \\
\text { deficiency }\end{array}$ & 5 & $25,785 \pm 5,829$ & 25,592 & $18,203-31,798$ \\
\hline $\begin{array}{l}\text { Maxillary deficiency + mandibular } \\
\text { excess }\end{array}$ & 15 & $24,912 \pm 9,193$ & 21,796 & $15,514-45,445$ \\
\hline $\begin{array}{l}\text { Mandibular excess + mandibular } \\
\text { deficiency }\end{array}$ & 4 & $20,225 \pm 4,364$ & 19,681 & $15,514-26,026$ \\
\hline \multicolumn{5}{|l|}{ Gender } \\
\hline Female & 28 & $24,670 \pm 8,039$ & 21,985 & $10,667-45,445$ \\
\hline Male & 13 & $21,835 \pm 5,334$ & 21,904 & $13,432-31,176$ \\
\hline \multicolumn{5}{|l|}{ Hypopharynx volume } \\
\hline \multicolumn{5}{|l|}{ Deformity } \\
\hline Mandibular deficiency & 9 & $2,356 \pm 1,284$ & 2,094 & $358-4,864$ \\
\hline Maxillary deficiency & 8 & $3,430 \pm 2,001$ & 3,435 & $1,147-6,163$ \\
\hline $\begin{array}{l}\text { Maxillary deficiency + mandibular } \\
\text { deficiency }\end{array}$ & 5 & $3,149 \pm 1,766$ & 3,268 & $600-5,246$ \\
\hline $\begin{array}{l}\text { Maxillary deficiency + mandibular } \\
\text { excess }\end{array}$ & 15 & $3,133 \pm 1,747$ & 2,991 & $683-7,308$ \\
\hline $\begin{array}{l}\text { Mandibular excess + mandibular } \\
\text { deficiency }\end{array}$ & 4 & $1,119 \pm 555$ & 1,121 & $522-1,712$ \\
\hline Gender & & $\sqrt{12}$ & & \\
\hline Female & 28 & $2,805 \pm 1,719$ & 2,591 & $522-7,308$ \\
\hline Male & 13 & $2,872 \pm 1,733$ & 2,204 & $358-5,775$ \\
\hline \multicolumn{5}{|l|}{ Nasopharynx volume } \\
\hline \multicolumn{5}{|l|}{ Deformity } \\
\hline Mandibular deficiency & 9 & $7,148 \pm 1,837$ & 7,266 & $4,448-10,041$ \\
\hline Maxillary deficiency & 8 & $5,534 \pm 1,636$ & 5,809 & $3,210-8,086$ \\
\hline $\begin{array}{l}\text { Maxillary deficiency + mandibular } \\
\text { deficiency }\end{array}$ & 5 & $5,293 \pm 2,343$ & 6,339 & $1,674-7,149$ \\
\hline $\begin{array}{l}\text { Maxillary deficiency + mandibular } \\
\text { excess }\end{array}$ & 15 & $5,295 \pm 2,334$ & 5,731 & $1,780-8,811$ \\
\hline $\begin{array}{l}\text { Mandibular excess + mandibular } \\
\text { deficiency }\end{array}$ & 4 & $5,781 \pm 536$ & 5,868 & $5,077-6,312$ \\
\hline \multicolumn{5}{|l|}{ Gender } \\
\hline Female & 28 & $6,267 \pm 1,881$ & 6,329 & $1,780-10,041$ \\
\hline Male & 13 & $4,781 \pm 2,076$ & 4,223 & $1,674-8,014$ \\
\hline \multicolumn{5}{|l|}{ Oropharynx volume } \\
\hline \multicolumn{5}{|l|}{ Deformity } \\
\hline Mandibular deficiency & 9 & $13,483 \pm 4,998$ & 11,157 & $8,030-21,309$ \\
\hline Maxillary deficiency & 8 & $14,063 \pm 6,583$ & 15,223 & $1,101-22,824$ \\
\hline $\begin{array}{l}\text { Maxillary deficiency + mandibular } \\
\text { deficiency }\end{array}$ & 5 & $17,344 \pm 4,595$ & 18,781 & $12,343-22,191$ \\
\hline $\begin{array}{l}\text { Maxillary deficiency + mandibular } \\
\text { excess }\end{array}$ & 15 & $16,484 \pm 6,403$ & 13,415 & $9,506-31,633$ \\
\hline $\begin{array}{l}\text { Mandibular excess + mandibular } \\
\text { deficiency }\end{array}$ & 4 & $13,326 \pm 3,912$ & 12,232 & $9,915-18,923$ \\
\hline \multicolumn{5}{|l|}{ Gender } \\
\hline Female & 28 & $15,599 \pm 6,498$ & 13,391 & $1,101-31,633$ \\
\hline Male & 13 & $14,183 \pm 3,512$ & 13,893 & $8,801-18,923$ \\
\hline
\end{tabular}

Abbreviation: SD, standard deviation.

dos Santos et al. Correlation Between Airway Volume and MCA Location. J Oral Maxillofac Surg 2020.

617

618

619

620

621

622

623

624

625

626

627

628

629

630

631

632

633

634

635

636

637

638

639

640

641

642

643

644

645

646

647

648

649

650

651

652

653

654

655

656

657

658

659

660

661

662

663

664

665

666

667

668

669

670

671

672 
Table 4. DESCRIPTIVE STATISTICS OF MCA STRATIFIED BY LOCATION

\begin{tabular}{lcccc} 
MCA Location & Patients $(\mathrm{n})$ & Mean $\pm \mathrm{SD}\left(\mathrm{mm}^{3}\right)$ & Median $\left(\mathrm{mm}^{3}\right)$ & Range $\left(\mathrm{mm}^{3}\right)$ \\
\hline Hypopharynx & & & & \\
Nasopharynx & 8 & $109.13 \pm 72.39$ & 87.00 & $46.00-278.00$ \\
Oropharynx & 14 & $179.29 \pm 89.25$ & 172.50 & $54.00-388.00$ \\
\hline
\end{tabular}

Abbreviations: MCA, maximum constriction area; SD, standard deviation.

dos Santos et al. Correlation Between Airway Volume and MCA Location. J Oral Maxillofac Surg 2020.

\section{Discussion}

The purpose of the present study was to assess the posterior airway volume and the location of the MCA in patients who had presented for correction of a dentofacial deformity through orthognathic surgery and to correlate them with the type of facial deformity, diagnosed clinically and cephalometrically. After the clinical diagnosis had been determined using photographic and cephalometric records, airway measurements were performed on CBCT images using the Dolphin Imaging airway tool. Our hypothesis was that the location of the MCA and the airway area with the smaller volume would have a direct relationship with the clinical diagnosis of the deformity and, hence, would influence the surgeon's decision on which procedure should be performed.

Previous studies have discussed airway volume changes but correlated them with the type of occlusion and did specify the clinical diagnosis in relationship to the facial anatomy. It is common knowledge that a Class III malocclusion can be represented by maxillary deficiency or mandibular excess, or a combination of both. Normal Class I occlusion can be achieved by advancing the maxilla or setting back the mandible, or a combination of these 2 procedures

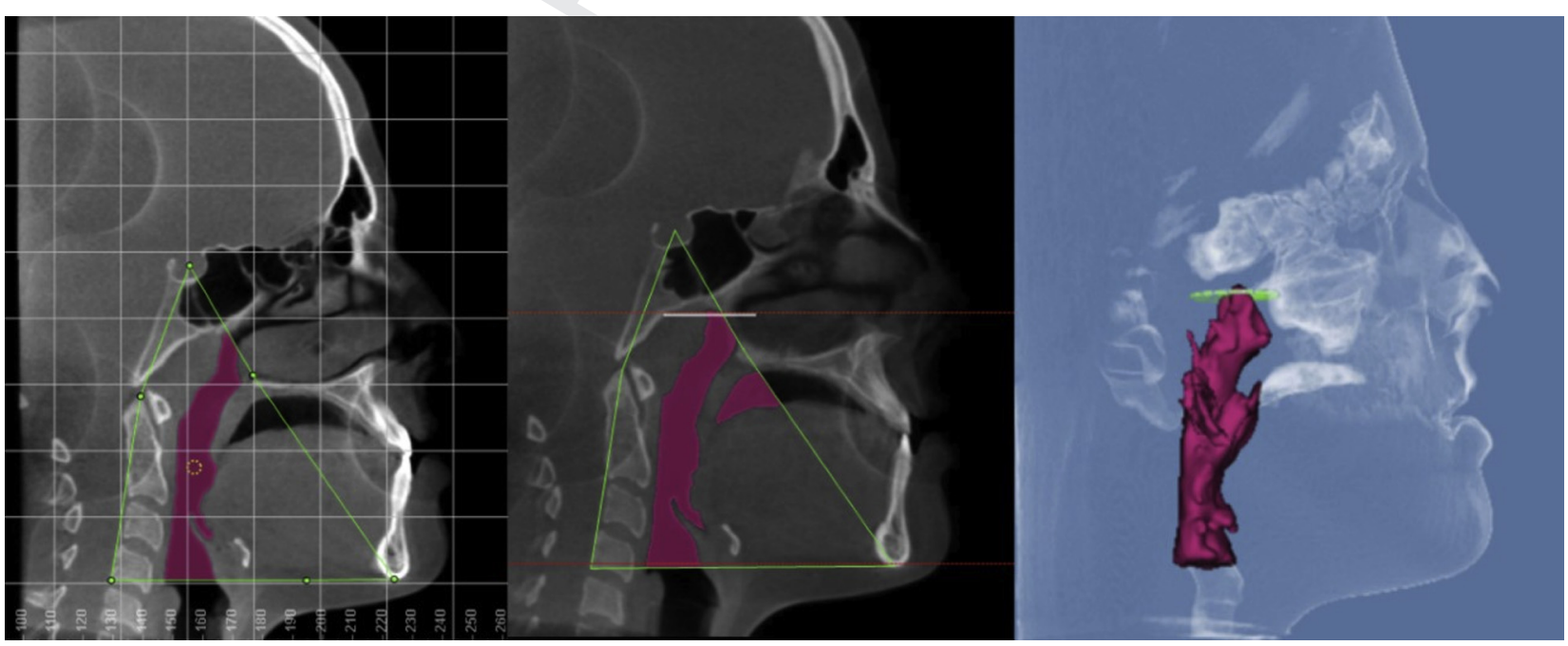

FIGURE 2. Images of a patient with maxillary deficiency showing maximum constriction area limits and location.

dos Santos et al. Correlation Between Airway Volume and MCA Location. J Oral Maxillofac Surg 2020. (2-jaw surgery). Usually, esthetic parameters are considered when deciding which jaw to move in which direction and by what magnitude. By analyzing the airway volume in the different segments and the MCA and correlating it with the type of facial deformity, we sought to provide more evidence for considering the airway characteristics when defining the jaw movements during orthognathic surgery.

Our sample included 5 different types of dentofacial deformities, in agreement with the most common deformities treated surgically in the field of orthognathic surgery. The present study used the N-P line derived from reconstructed cephalometric images from СВСТ files and clinical photographs to diagnose the dentofacial deformities. The McNamara cephalometric parameter (N-P) is commonly used by surgeons in the diagnosis and treatment planning of orthognathic surgeries because of its reproducible clinical parameters. ${ }^{16,17}$

We compared the airway volume, MCA, and MCA location among the different dentofacial deformities using the 3D airway tool in Dolphin software, which uses segmentation algorithms to select and identify the structures according to sensitivity. Sensitivity is the description of how the software tool analyzes 


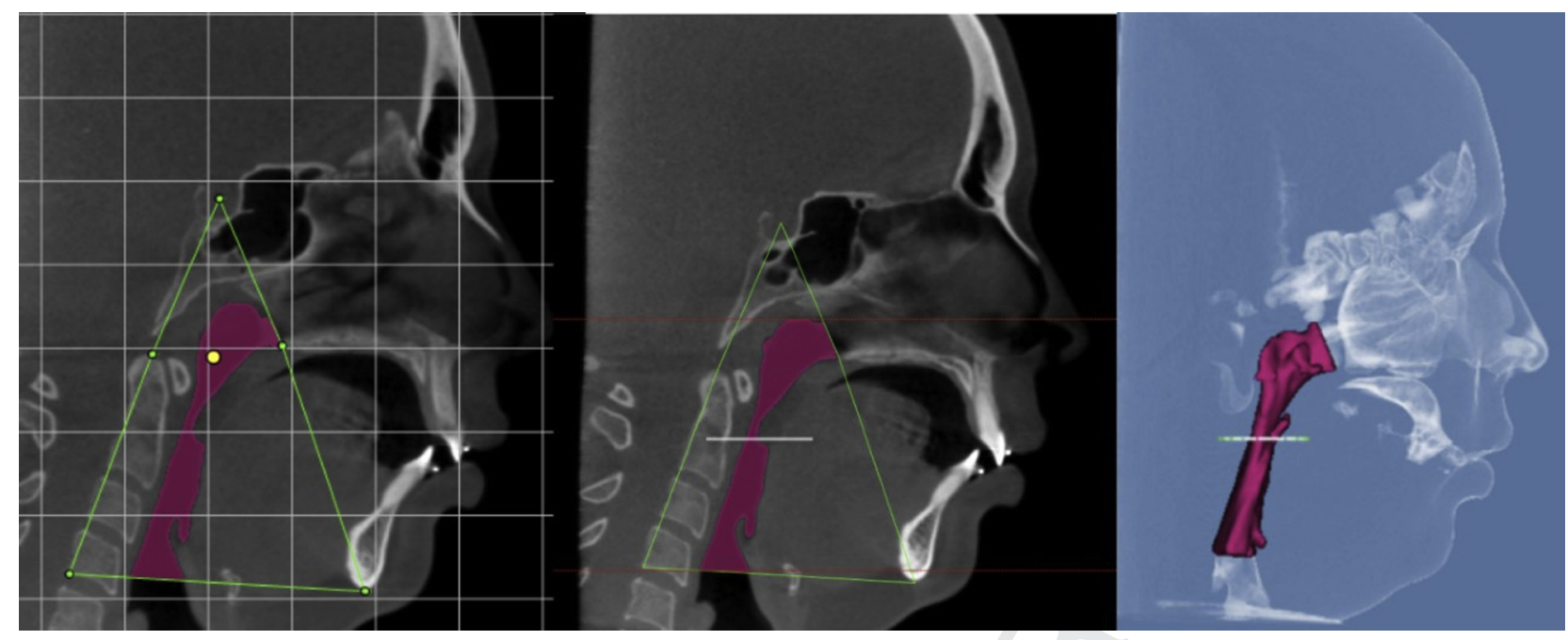

FIGURE 3. Images of a patient with mandibular deficiency showing maximum constriction area limits and location. dos Santos et al. Correlation Between Airway Volume and MCA Location. J Oral Maxillofac Surg 2020. and reads the differences in the density of anatomic structures. It can be influenced by factors such as the exposition when obtaining the images and the use of different software algorithms. In our series, the value of 50 was found to be the one that segmented the less dense airway structure from the surrounding denser bone structures, providing a uniform visual segmentation of the airway inside the defined boundaries. Because all CBCT scans had been performed using the same equipment, a fixed sensitivity value of 50 was set for all airway evaluations. This was similar to the study by Fagala, ${ }^{18}$ in which a sensitivity value of 45 was used.

A number of investigators have reported conflicting data regarding the influence of gender, with some reporting no statistically significant differences between males and females. ${ }^{15,19-21}$ Alves et $\mathrm{al}^{22}$ demonstrated a statistically significant difference between males and females, with males having greater volumes. Grauer et $\mathrm{al}^{23}$ also showed that Class III male patients had larger nasopharynx volumes than did females. In the present study, the 28 female patients had presented with a larger mean airway volume compared with that of the 13 male patients; however, this difference was not statistically significant.

One limitation of our study was that we did not record the patients' BMI. In addition, data on sleep apnea (eg, an Epworth or STOP-BANG score) had not been recorded in the medical records. However, none of our patients were considered obese, and none had reported obstructive sleep apnea as their chief complaint. We had recruited our patients from those who had required treatment using orthognathic surgery for occlusal and esthetic concerns. Because the airway analysis is an important factor to be considered, we analyzed the airway and correlated the volume with the presented dentofacial deformity. The BMI can influence the airway volume but might not

\section{Table 5. DENTOFACIAL DEFORMITIES STRATIFIED BY GENDER AND MCA LOCATION}

\begin{tabular}{|c|c|c|c|c|c|}
\hline Variable & $\begin{array}{l}\text { Mandibular } \\
\text { Deficiency }\end{array}$ & $\begin{array}{l}\text { Maxillary } \\
\text { Deficiency }\end{array}$ & $\begin{array}{c}\text { Maxillary } \\
\text { Deficiency + Mandibular } \\
\text { Deficiency }\end{array}$ & $\begin{array}{c}\text { Maxillary } \\
\text { Deficiency }+ \text { Mandibular } \\
\text { Excess }\end{array}$ & $\begin{array}{c}\text { Vertical Maxillary } \\
\text { Excess + Mandibular } \\
\text { Deficiency }\end{array}$ \\
\hline \multicolumn{6}{|l|}{ Gender } \\
\hline Female & $7(77.8)$ & $4(50)$ & $3(60)$ & $11(73.3)$ & $3(75)$ \\
\hline Male & $2(22.2)$ & $4(50)$ & $2(40)$ & $4(26.7)$ & $1(25)$ \\
\hline \multicolumn{6}{|l|}{ MCA location } \\
\hline Hypopharynx & $1(11.1)$ & $2(25)$ & $0(0)$ & $4(26.7)$ & $1(25)$ \\
\hline Nasopharynx & $0(0)$ & $3(37.5)$ & $2(40)$ & $8(53.3)$ & $1(25)$ \\
\hline Oropharynx & $8(88.9)$ & $3(37.5)$ & $3(60)$ & $3(20)$ & $2(50)$ \\
\hline
\end{tabular}

Data presented as $\mathrm{n}(\%)$.

Abbreviation: MCA, maximum constriction area.

dos Santos et al. Correlation Between Airway Volume and MCA Location. J Oral Maxillofac Surg 2020. 
have greater influence on the MCA location than the skeletal deformity. Future studies correlating the BMI and MCA for different deformities should be conducted.

In relation to skeletal deformities, our findings have shown that mean total airway volumes did not demonstrate statistically significant differences among the 5 groups. However, when the posterior airway was segmented, the nasopharynx volume was significantly smaller in those with maxillary deficiency plus mandibular excess compared with those with mandibular deficiency. The hypopharynx volume was significantly smaller in those with vertical maxillary excess plus mandibular deficiency compared with those maxillary deficiency or maxillary deficiency plus mandibular excess.

The patients with mandibular excess had a mean total airway volume smaller than that of those with mandibular deficiency $\left(25,785.40 \mathrm{~mm}^{3}\right.$ for maxillary deficiency plus mandibular deficiency vs $24,912.20 \mathrm{~mm}^{3}$ for maxillary deficiency plus mandibular excess). In our sample, no patient had a diagnosis of isolated mandibular excess, which might have been because those with maxillary deficiency plus mandibular excess (Class III) had a more posteriorly positioned maxilla compared with the patients with maxillary deficiency plus mandibular deficiency (Class II). Differing BMIs could be another explanation.

The MCA expresses the location of the smallest axial size of the posterior airway. Shokri et $\mathrm{al}^{14}$ found no statistical significance among the 3 skeletal malocclusion classes, although the location in most of their study population was the oropharynx. In our study, the comparison of the MCA location among the identified dentofacial deformity groups showed no statistically significant differences. The Fisher exact test was used to evaluate the association between MCA location and dentofacial deformity. When the 5 individual deformities were retained for the association with MCA location, the results did not reach statistical significance $(P=.0588)$. However, when the deformities were combined into 3 levels because of the small sample sizes-mandibular deficiency only, maxillary deficiency only, or both - the association was statistically significant $(P=.0224)$, with a lower percentage of maxillary deficiency only in the patients with the MCA located in the oropharynx.

In our sample, the MCA location was more often seen in the nasopharynx for those with maxillary deficiency and in the oropharynx for those with mandibular deficiency. This latter finding is congruent with the findings reported by Claudino et $\mathrm{al}^{2}{ }^{2}$ who had also found the MCA location to be in the oropharynx for skeletal Class II patients.

The location of the airway MCA seems to have a strong correlation with the horizontal position of the maxilla and mandible. Maxillary deficiencies (isolated or combined) had the MCA at the nasopharynx and mandibular deficiencies (isolated or combined) had the MCA at the oropharynx.

In conclusion, we found that the airway volume and the MCA location are influenced by the maxillomandibular morphology. Patients whose skeletal deformity included maxillary deficiency, isolated or with mandibular excess, had had a smaller nasopharynx volume than patients with mandibular deficiency. In contrast, patients with mandibular deficiency, isolated or with vertical maxillary excess, demonstrated smaller hypopharynx volume than patients with maxillary deficiencies, regardless of whether mandibular excess was present.

The location of the MCA is a factor that should be considered when planning orthognathic surgical procedures, in addition to the classic occlusion and facial aesthetic analysis. In our sample, although small, a trend was noted for the MCA location to be positioned more often in the nasopharynx in patients with maxillary deficiency and in the oropharynx in patients with mandibular deficiency. However, the difference was not statistically significant. These findings bring supporting evidence to what has been considered a common assumption-that horizontally deficient jaws influence the location of the MCA.

When performing treatment planning for orthognathic surgical procedures, the occlusal, esthetic, and airway parameters should be considered. By understanding the location of the MCA and the area with the smaller airway volume, the treatment plan can maximize advancement of the deficient region, as long as that is esthetically feasible, once normal occlusion can be achieved with any jaw movement. An initial immediate postoperative analysis of our own sample (report in preparation) will allow us to explore the correlation between the magnitude of advancement and the effects on the airway volume and MCA position. Future studies on this topic are required with a larger number of patients, comparisons of the pre- and postoperative CBCT images using the same method to confirm whether an increase in volume or a change in the MCA location occurs when procedures are performed.

\section{References}

1. Castro-Silva L, Monnazzi MS, Spin-Neto R, et al: Cone-beam evaluation of pharyngeal airway space in class I, II, and III patients. Oral Surg Oral Med Oral Pathol Oral Radiol 120:679, 2015

2. Claudino LV, Mattos CT, Ruellas AC, Sant'Anna EF: Pharyngeal airway characterization in adolescents related to facial skeletal pattern: A preliminary study. Am J Orthod Dentofacial Orthop 143:799, 2013

3. Butterfield KJ, Marks PL, McLean L, Newton J: Linear and volumetric airway changes after maxillomandibular advancement for obstructive sleep apnea. J Oral Maxillofac Surg 73:1133, 2015 
4. Gonçales E, Duarte M, Palmieri C Jr, et al: Retrospective analysis of the effects of orthognathic surgery on the pharyngeal airway space. J Oral Maxillofac Surg 72:2227, 2014

5. Abramson ZR, Susarla S, Tagoni JR, Kaban L: Three-dimensional computed tomographic analysis of airway anatomy. J Oral Maxillofac Surg 68:363, 2010

6. Brunetto DP, Velasco L, Koerich L, Araujo MT: Prediction of 3dimensional pharyngeal airway changes after orthognathic surgery: A preliminary study. Am J Orthod Dentofacial Orthop 146:299, 2014

7. El H, Palomo JM: Measuring the airway in 3 dimensions: A reliability and accuracy study. Am J Orthod Dentofacial Orthop 137(suppl):S50.e1, 2010

8. Smith T, Ghoneima A, Stewart K, et al: Three-dimensional computed tomography analysis of airway volume changes after rapid maxillary expansion. Am J Orthod Dentofacial Orthop 141:618, 2012

9. Weissheimer A, Menezes LM, Sameshima GT, et al: Imaging software accuracy for 3-dimensional analysis of the upper airway. Am J Orthod Dentofacial Orthop 142:801, 2012

10. Eslami E, Katz ES, Baghdady M, et al: Are three-dimensional airway evaluations obtained through computed and conebeam computed tomography scans predictable from lateral cephalograms? A systematic review of evidence. Angle Orthod 87:159, 2017

11. Aboudara C, Nielsen I, Huang JC, et al: Comparison of airway space with conventional lateral head films and 3-dimensional reconstruction from cone-beam computed tomography. Am J Orthod Dentofac Orthop 135:468, 2009

12. Loubele M, Guerrero ME, Jacobs R, et al: A comparison of jaw dimensional and quality assessments of bone characteristics with cone-beam CT, spiral tomography, and multi-slice spiral CT. Int J Oral Maxillofac Implants 22:446, 2007
13. El H, Palomo JM: Airway volume for different dentofacial skeletal patterns. Am J Orthod Dentofacial Orthop 139:e511, 2011

14. Schendel SA, Hatcher D: Automated 3-dimensional airway analysis from cone-beam computed tomography data. J Oral Maxillofac Surg 68:696, 2010

15. Shokri A, Miresmaeili A, Ahmadi A, et al: Comparison of pharyngeal airway volume in different skeletal facial patterns using cone beam computed tomography. J Clin Exp Dent 10:e1017, 2018

16. Kula K, Ghoneima A: Cephalometry in orthodontics: 2D and 3D (ed 1). Berlin, Germany, Quintessence International Publishing, 2018

17. Jacobson A, Jacobson RL: Radiographic Cephalometry: From Basics to 3-D Imaging. Berlin, Germany, Quintessence International Publishing, 2006

18. Fagala KD: A CBCT analysis of class I and II orthodontic cases: A correlative study of airway morphology and facial form. Memphis, TN, University of Tennessee Health Science Center, 2013

19. Handelman CS, Osborne G: Growth of the nasopharynx and adenoid development from one to eighteen years. Angle Orthod 46:243, 1976

20. Klein JC: Nasal respiratory function and craniofacial growth. Arch Otolaryngol Head Neck Surg 112:843, 1986

21. Solow B, Siersbaek-Nielsen S, Greve E: Airway adequacy, head posture, and craniofacial morphology. Am J Orthod 86:214, 1984

22. Alves M Jr, Franzotti ES, Baratieri C, et al: Evaluation of pharyngeal airway space amongst different skeletal patterns. Int $\mathrm{J}$ Oral Maxillofac Surg 41:814, 2012

23. Grauer D, Cevidanes LS, Styner MA, et al: Pharyngeal airway volume and shape from cone-beam computed tomography: Relationship to facial morphology. Am J Orthod Dentofacial Orthop 136:805, 2009 